Provided for non-commercial research and educational use only. Not for reproduction or distribution or commercial use.

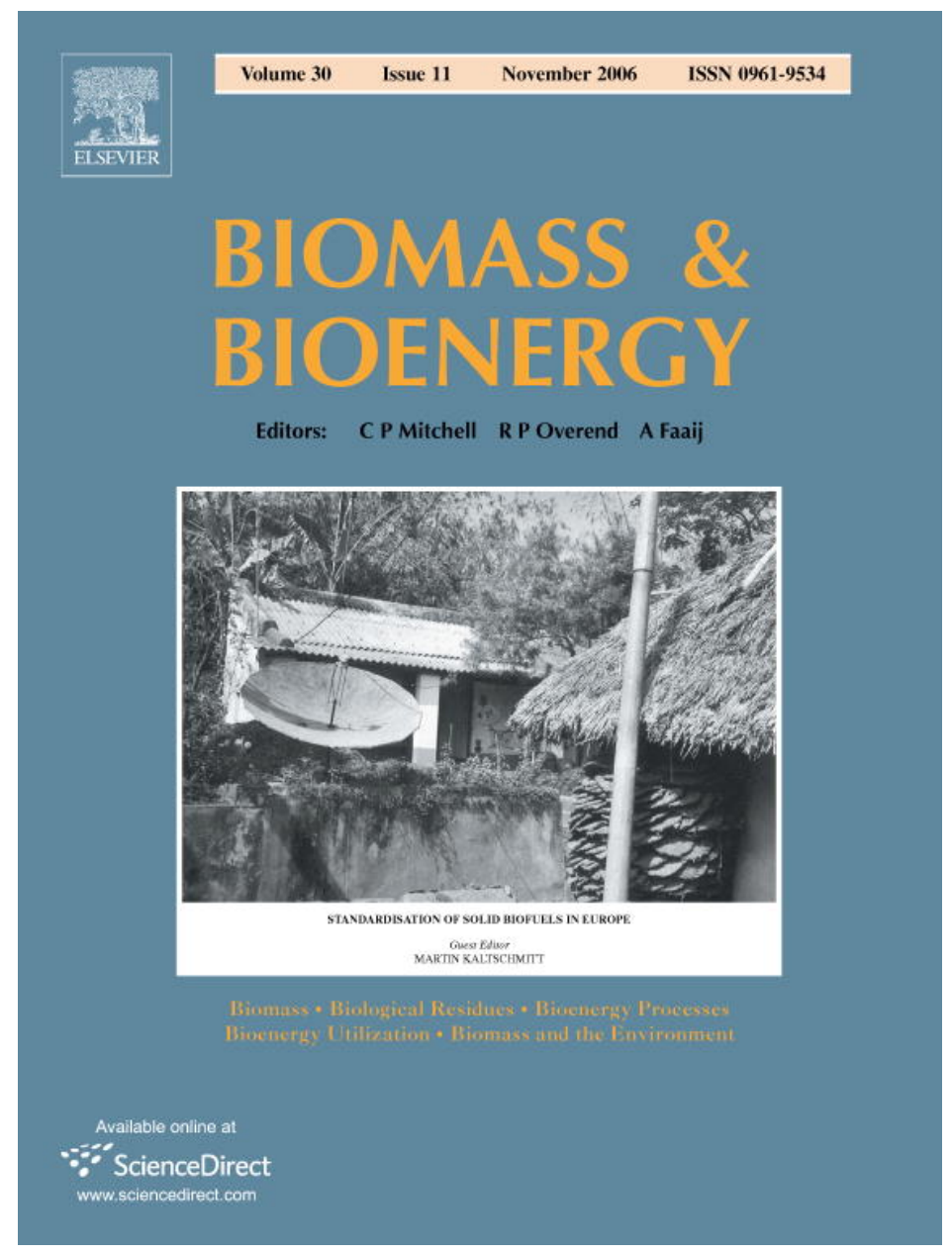

This article was originally published in a journal published by Elsevier, and the attached copy is provided by Elsevier for the author's benefit and for the benefit of the author's institution, for non-commercial research and educational use including without limitation use in instruction at your institution, sending it to specific colleagues that you know, and providing a copy to your institution's administrator.

All other uses, reproduction and distribution, including without limitation commercial reprints, selling or licensing copies or access,

or posting on open internet sites, your personal or institution's website or repository, are prohibited. For exceptions, permission may be sought for such use through Elsevier's permissions site at: 


\title{
Methods for size classification of wood chips
}

\author{
Hans Hartmann ${ }^{\mathrm{a}, *}$, Thorsten Böhm ${ }^{\mathrm{a}}$, Peter Daugbjerg Jensen ${ }^{\mathrm{b}}$, Michaël Temmerman ${ }^{\mathrm{c}}$, \\ Fabienne Rabier $^{\mathrm{c}}$, Michael Golser ${ }^{\mathrm{d}}$ \\ ${ }^{a}$ Technologie- und Förderzentrum im Kompetenzzentrum für Nachwachsende Rohstoffe (TFZ), Schulgasse 18, D-94315 Straubing, Germany \\ ${ }^{\mathrm{b}}$ Forest and Landscape-FLD, The Royal Veterinary and Agricultural University, Rolighedsvej 23, DK-1958 Frederiksberg C, Denmark \\ ${ }^{\mathrm{c} C e n t r e}$ wallon de Recherches agronomiques-CRA-W-Département Génie rural, 146, Chaussée de Namur, B-5030 Gembloux, Belgium \\ ${ }^{\mathrm{d}}$ Holzforschung Austria-HFA-Franz Grill-Straße 7, A-1031 Wien, Austria
}

Received 17 November 2005; accepted 9 June 2006

Available online 12 September 2006

\begin{abstract}
Methods for size classification of wood chips were analysed in an international round robin using 13 conventional wood chip samples and two specially prepared standard samples, one from wood chips and one from hog fuel. The true size distribution of these two samples (according to length, width and height) had been determined stereometrically (reference method) using a digital calliper gauge and by weighing each of the about 7000 wood particles per sample. Five different horizontal and three rotary screening devices were tested using five different screen hole diameters $(3.15,8,16,45,63 \mathrm{~mm}$, round holes). These systems are compared to a commercially available continuously measuring image analysis equipment.

The results show that among the devices of a measuring principle - horizontal and rotary screening - the results are quite comparable, while there is a severe incompatibility when distributions are determined by different measuring principles. Highest conformity with the reference values is given for measurements with an image analysis system, whereas for all machines with horizontal screens the median value of the size distribution only reached between one-third to half of the reference median value for the particle length distribution. These deviations can be attributed to a higher particle misplacement, which is particularly found in the larger fractions. Such differences decrease when the particle's shape is more roundish (i.e. sphericity closer to one). The median values of length distributions from screenings with a rotary classifier are between the measurements from an image analysis and horizontal screening devices.
\end{abstract}

(C) 2006 Elsevier Ltd. All rights reserved.

Keywords: Wood chips; Hog fuel; Size classification; Particle size distribution; Horizontal screening; Rotary screening; Image analysis; Sphericity

\section{Introduction}

Particle size distribution influences the handling and combustion characteristics of solid particulate biofuels. Storage and ventilation properties are affected [1]. Bridging tendency, which is critical for an undisturbed fuel conveying, increases with long and thin particles [2,3]. Energy conversion and emissions are also influenced by the particle sizes, particularly for sawdust [4].

For fuel chips, mechanically or manually operated screening devices are commonly applied and there is a large variety of applicable systems. The screens are usually arranged in a tower of several sieves, which are clamped to each other,

\footnotetext{
*Corresponding author. Tel.: + 499421300112 ; fax: + 499421300111.

E-mail address: hans.hartmann@tfz.bayern.de (H. Hartmann).
}

starting with the largest aperture size on top (Fig. 1). They are operating in a one-, two- or three-dimensional screen shaking movement sorting the particles by decreasing size. This type of determination of particle size distribution of wood chips is described in a number of standards [5-8].

Recently some measuring alternatives to the common flat screens have been discussed for use in wood fuel quality determination [9]. One of the options is an arrangement of several cylindrical sieves, which form a rotary screen starting with the lower aperture size and sorting the particles by increasing size (Fig. 1). The horizontal screening and the rotary classifier belong to the gravimetric method, which all have the problem that long and thin particles can pass small aperture widths while being in a vertical orientation, and they are thus wrongly allocated, if a separation by length is desired. 

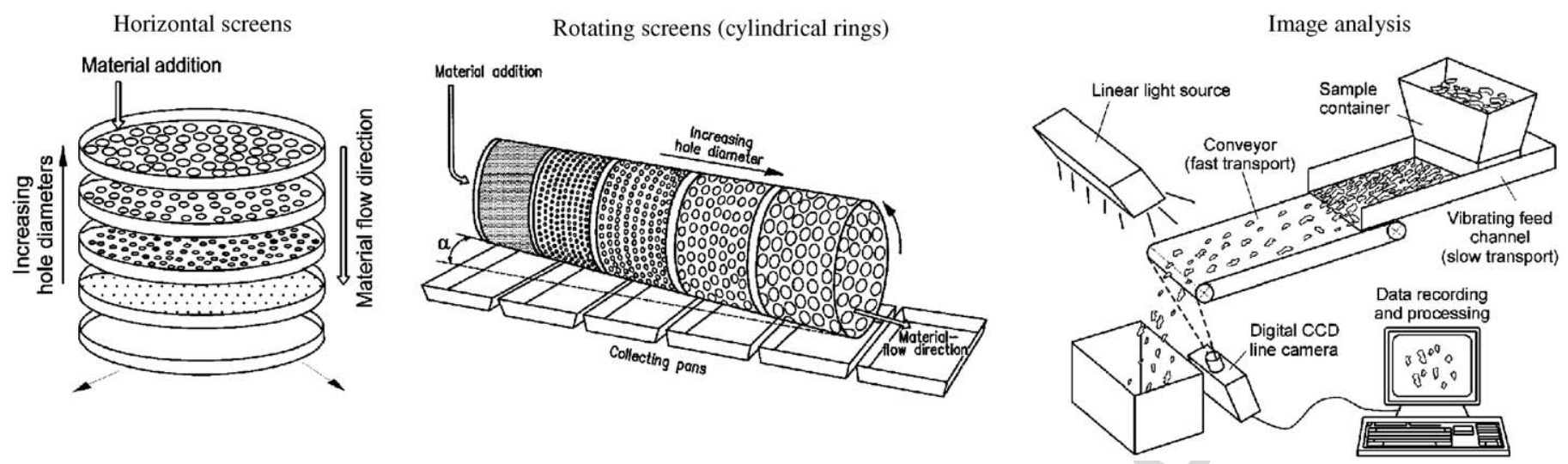

Fig. 1. Functioning principles of screening and image analysis classification methods for wood chips classification.

Such disadvantages are overcome by the application of a dynamic online image analysis system (Fig. 1). This technique is particularly interesting as it can sort the particle sizes according to more than just one size parameter. However, the image analysis is sensitive towards particle overlappings, resulting in overestimation of particle sizes $[9,10]$. A proper separation of the particles is thus an important prerequisite for an accurate size determination.

A reliable way of size determination is by hand, using callipers. However, such a stereometric measurement is generally too time consuming for routine operations and it is therefore only applicable for measurements on reference materials.

The measuring principles described are also based on different physical assumptions. The gravimetric methodsand also the stereometric method-are indirect methods where all particles are initially separated to size fractions before they are converted to mass fractions by weighing. The measurement therefore implies the hypothesis that the density of smaller and larger particles is more or less constant in order to allow conclusions on the size fractions by weighing. Density differences or inconsistent moisture contents would disturb the accuracy of the measurement. For the optical method, however, density differences are irrelevant, as the size measurement is made directly by regarding the projection of each particle shape.

In order to achieve comparable measurements, it is important to know to what degree the determination methods are compatible and which are the influencing factors. Such knowledge is particularly required for the currently ongoing elaboration of European biofuel standards. In this research, the goal was to determine any systematic differences between the methods and to evaluate the influencing factors.

\section{Materials and methods}

\subsection{Test material and sample preparation}

Two standard fuel samples were produced from wood chips and hog fuel as distinguished in the new Technical
Specification for solid biofuels [11]. The chip sample (SF1) consisted of 6036 particles (volume 9.11) and the hog fuel sample (SF2) consisted of 7534 particles (volume 7.21) (Fig. 2). For each particle, all three dimensions (length, width and thickness) were measured using a digital calliper (Mahr 16ES) with an accuracy of $0.01 \mathrm{~mm}$ (Fig. 3). In order to reduce human errors in these measurements, the readings were electronically transmitted to an Excel data sheet. Additionally, the weight of each particle was determined with an accuracy of $0.001 \mathrm{~g}$ at constant temperature and humidity. The length was measured as the maximum expansion of the particles. The width was recorded as the second longest expansion perpendicular to the length, while the thickness was the third longest expansion perpendicular to both, length and width.

The particles were hand sorted by length into five size classes. They were then coloured by different stain colour (in water bath) and dried. Each colour represents one of five size classes following the same size sequence as applied for the screening devices: $3.15-8 \mathrm{~mm}$ (1, orange), $8-16 \mathrm{~mm}$ (2, green), 16-45 mm (3, yellow), 45-63 mm (4, red) and over $63 \mathrm{~mm}$ (5, black). The colouring was intended to enable an easy selecting and weighing of all wrongly allocated particles from any sieving tray.

In order to enable conclusions on the influence of the particle shape, a second standard sample (SF2) was designed following the same length distribution as the first standard sample (SF1) but using hog fuel. The conformity of length properties was achieved by a constant monitoring of all changes in the size distribution curve which were caused by each particle added. Particles for SF2 were thus selected to achieve a best possible fit to the cumulative length distribution curves of SF1 (Fig. 4). The hog fuel sample (SF2) had more longish and thin shaped particles (mean length-width ratio: 3.6 ) while the wood chip sample (SF1) consisted of more square-like particle shapes with a mean length-width ratio of 1.9 .

Additionally to the two standard samples, 13 wood fuel samples of approximately 81 volume were produced using four different chipper types. Eight samples were from debarked round wood of spruce (one disc, one drum, one 

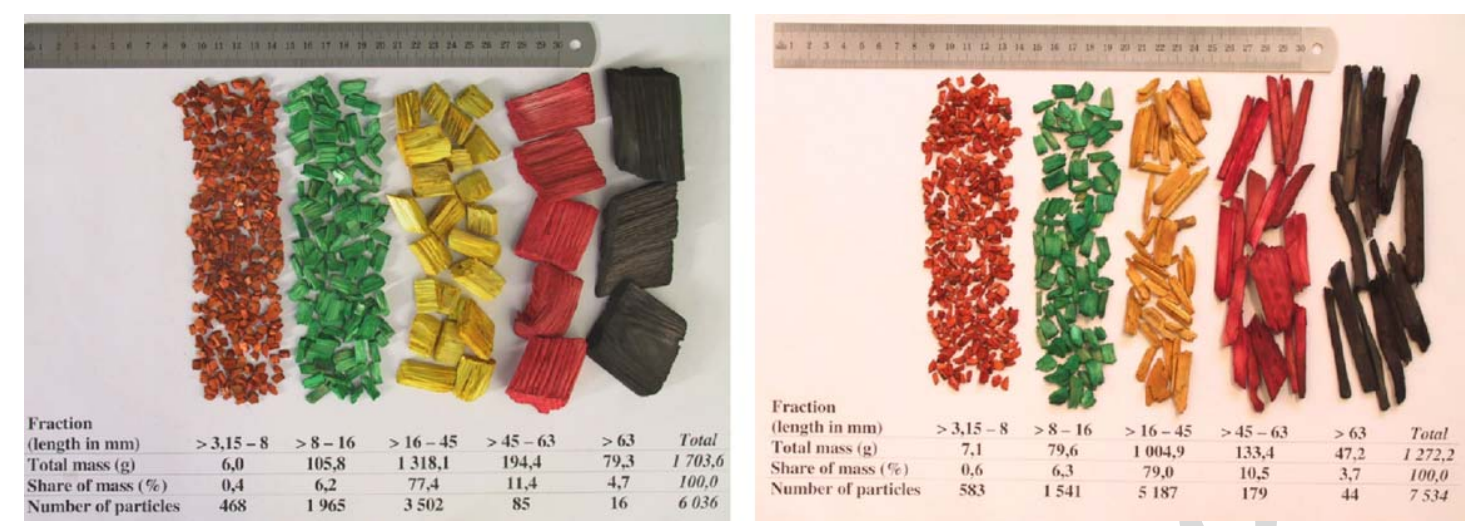

Fig. 2. Example of particles in the manually prepared and coloured standard wood chip sample (SF1, left) and hog fuel sample (SF2, right).
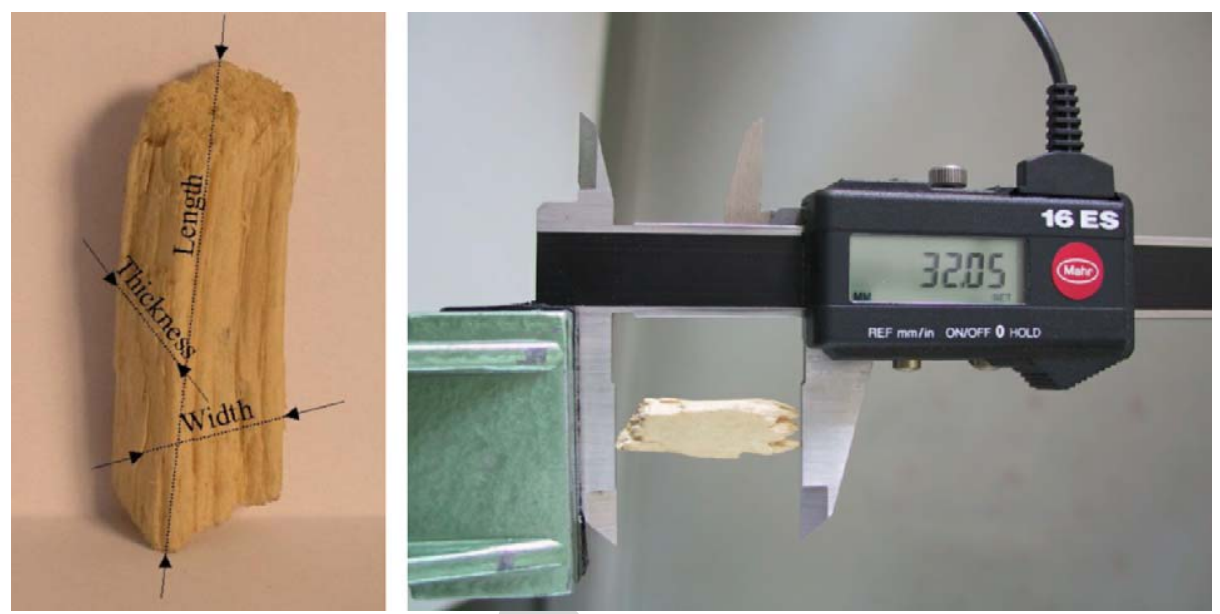

Fig. 3. Recording size data of a standard wood chip sample by manual size determination with a digital calliper gauge. Left: three measured dimensions of a particle; right: length determination with a digital calliper gauge.

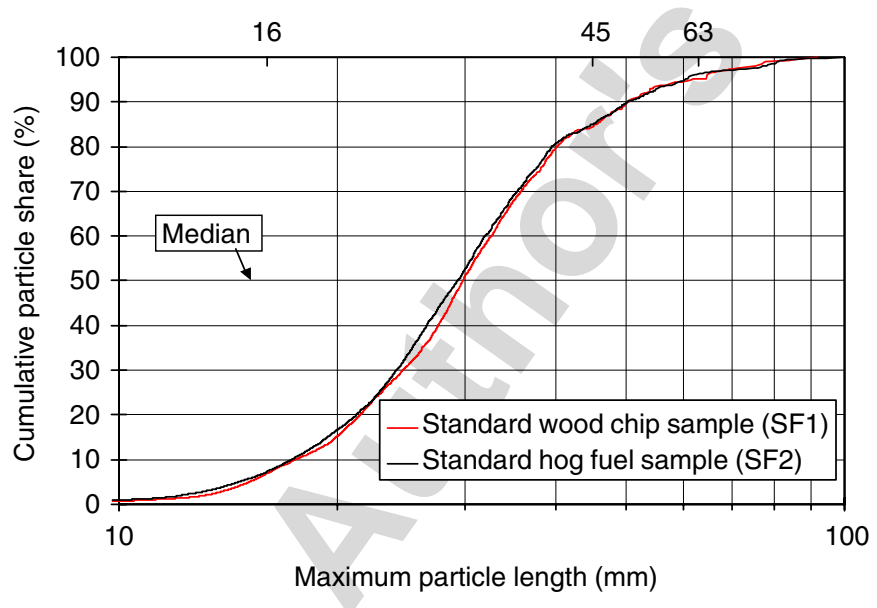

Fig. 4. Cumulative particle length distribution of the two standard samples (SF1 and SF2) according to stereometric length determinations.

spiral chipper, one shredder) and beech (one disc, one drum, one spiral chipper, one shredder). Furthermore, one sample of chipped short rotation coppice (poplar, disc chipper) and three samples from logging residues (two spruce, one beech, all by disc chipper).

\subsection{Size determination equipment}

\subsubsection{Gravimetric methods}

Five different horizontal sieves and one type of rotating sieve were used in the round robin (Table 1). The tested horizontal sieves applied different shaking movements either in a one-dimensional to and fro movement (device $1,2,3)$ or in circular, two-dimensional operation (device 4) or in a three-dimensional shaking mode (device 5), which means that additionally to the circular movement a horizontal motion is introduced, too.

The rotary screen classifiers consists of five joined cylindrical screening cylinders, each of $400 \mathrm{~mm}$ height having a $360 \mathrm{~mm}$ effective screening length (Fig. 1). The cylinders form a rotating drum of $500 \mathrm{~mm}$ diameter and $2230 \mathrm{~mm}$ total length. In opposition to horizontal screenings, fine particles are separated at the beginning of the screening process and are collected in the pan underneath. All particles larger than the widest screen holes of the last 
Table 1

Properties and screening parameters of devices tested in round robin trials

\begin{tabular}{|c|c|c|c|c|c|c|}
\hline Tested at/device & Type & Shaking movement & $\begin{array}{l}\text { Screen dimensions } \\
(\mathrm{mm})\end{array}$ & $\begin{array}{l}\text { Screen area } \\
\left(\mathrm{cm}^{2}\right)\end{array}$ & $\begin{array}{l}\text { Amplitude } \\
(\mathrm{mm})\end{array}$ & $\begin{array}{l}\text { Frequency } \\
\left(\min ^{-1}\right)\end{array}$ \\
\hline \multicolumn{7}{|c|}{ Horizontal screening } \\
\hline Lab 1 (1) & $\begin{array}{l}\text { Build according to } \\
\text { SCAN-CM 49:94 } \\
{[7]}\end{array}$ & One-dimensional & $\begin{array}{l}\text { Rectangular } \\
400 \times 650\end{array}$ & 2600 & 120 & $160 \pm 10$ \\
\hline Lab 2 (2) & Prototype by HFA & One-dimensional & $\begin{array}{l}\text { Rectangular } \\
500 \times 500\end{array}$ & 2500 & 60 & 300 \\
\hline Lab 3 (3) & $\begin{array}{l}\text { Stiletto Vibrating } \\
\text { table }\end{array}$ & One-dimensional & $\begin{array}{l}\text { Rectangular } \\
500 \times 500\end{array}$ & 2500 & $0.09-1.3$ & 3000 \\
\hline Lab 4 (4) & $\begin{array}{l}\text { Retsch AS } 400 \\
\text { control }\end{array}$ & Two-dimensional & Round $\varnothing 400$ & 1257 & 30 & $50-300$ \\
\hline Lab 4 (5) & $\begin{array}{l}\text { Haver \& Boecker } \\
\text { EML } 450\end{array}$ & Three-dimensional & Round $\varnothing 400$ & 1590 & $0.1-2.0$ & 3000 \\
\hline \multicolumn{7}{|l|}{ Rotary screening } \\
\hline Lab $1,3,4$ & Rotating screen & Rotating & $\begin{array}{l}\text { Cylindrical } \varnothing 500 \\
\text { Length } 400^{\mathrm{a}}\end{array}$ & $5655^{\mathrm{a}}$ & & \\
\hline
\end{tabular}

a $360 \mathrm{~mm}$ effective screening length when excluding the blind part at the stiffened ring connection.

ring are discharged into a final collecting pan. The inclination of the drum towards the horizontal ground $(\alpha)$ was $3.0^{\circ}$ and the drum rotated at a speed of $20 \mathrm{~min}^{-1}$. Due to the inclination of the drum, the remaining particles travel onward to the subsequent screening rings. The sample material is continuously fed over a slide tangentially onto the bottom of the first screening ring.

For all sievings (horizontal and rotary), identical sieve hole diameters were applied. They were round holes of $3.15,8,16,45$ and $63 \mathrm{~mm}$, all screens followed the requirements of ISO 3310-2 [12].

\subsubsection{Image analysis}

For the photo-optical analysis, a commercially available classifier was used (Haver-CPA 4 RT Band, by Haver \& Boecker, Germany). In this set-up, the sample is fed into a container, which serves as a feeder hopper discharging the particles to a vibrating feed canal. At the end of the canal the particles are dropped onto a conveyer belt which singularises the particles by transporting them at an approximately 22 times higher speed than on the vibrating feed canal (belt speed: $0.9 \mathrm{~m} \mathrm{~s}^{-1}$ ). Before the particles are falling off the end of the conveyer belt, they pass a linear light source whose light is continuously registered by a digital CCD horizontal line camera on the opposite side of the light source (see Fig. 1). This camera records 4096 pixels over a width of $400 \mathrm{~mm}$, thus the resolution per pixel is $98 \mu \mathrm{m}$. The camera processes 40 million pixels per second, whereby the matrix-equivalent resolution conforms to 24 megapixels. When a particle passes the projection plane of the camera, the incoming light is disturbed at a width, which is proportional to the particle's momentary horizontal expansion. From the retention time within the camera's scope and the recordings for the varying horizontal expansion, the size of each particle's shadow is recorded and calculated by a computer. This calculation assumes a constant particle velocity at the measuring plane. Overlapping particles are identified as one particle of respectively larger dimension. Therefore, the singularisation as well as the horizontal spreading of the particles on the conveyer belt needs to be controlled carefully.

\subsection{Measuring procedure}

All round robin partners followed common guidelines, which were elaborated based on the experience from pretests. Prior to measurements, the 15 samples were placed in the laboratory under constant climate conditions for minimum $24 \mathrm{~h}$, thus avoiding any larger moisture changes during the processing. In all trials, the sample size was around 81 ; samples were homogenised by hand before the tests. To identify any particle losses during measurement, the mass of the samples was determined prior to the tests.

For the horizontal shaking screens, a maximum sample layer of approximately $5 \mathrm{~cm}$ was placed on the upper tray. In case more sample material had to be determined, the sample was divided in halves and the procedure was repeated, then the masses of the different fractions were unified and weighed. From preliminary tests, the duration of the screening operations was set between 11 and $16 \mathrm{~min}$, depending on the specific device. In pre-tests, any further screening had led to insignificant mass changes of below $0.3 \% \mathrm{~min}^{-1}$, determined between any two consecutive sieves, related to the total sample mass. Any particles sticking in the holes of a tray were added to the sieve oversizes of the respective tray.

In the rotary screening device, the samples were placed in eight equal 1-1 heaps on a tray from where they were slowly poured by hand into the infeed slide of the drum. Thus, a more or less constant feeding rate of $11 \mathrm{~min}^{-1}$ was achieved. 
In case that particles were found as sieve oversize on the 63-mm screen (in horizontal screening) or were discharged from the $63-\mathrm{mm}$ sieve to the final collecting pan (in rotary screening), the maximum expansion of the largest particle was measured by hand using a calliper gauge. This information was required for the calculation of the mean particle size and the size distribution curve.

For horizontal screenings all samples were tested at four laboratories (five different devices) in three replications. Rotary screenings were tested at three laboratories (three devices) in three replications per sample. For the image analysis, the number of replications was increased to five in order to gain enough results for repeatability calculations since this equipment was available at only one partner. The feeding rate was set individually for each fuel, whereby it was attempted to minimise overlapping particles or particles tangent to each other as much as possible by visual inspection. These overlappings were higher for fine than for coarse fuels, thus the processing duration for each $8-1$ sample varied between 5 and $20 \mathrm{~min}$. In all trials, the online classification was made according to the maximum particle expansion applying the "maximum length mode" of the device. This length is calculated from the identified longest distance between two pixels of a computed cohesive particle area, it is then defined as the length axis. The maximum width of a particle is calculated from the longest distance between two pixels on the axis perpendicular to the length axis. This is done simultaneously with the length determination.

\subsection{Calculation procedures}

For data evaluation and statistical processing, the measured size allocations were reduced to a single parameter. Here the median value of the particle collective was chosen because it is less susceptible towards extreme values or outliers than the mean particle size. This applies for example when few bigger particles do not fall through a designated screen hole. The median value is defined as the calculated particle size where $50 \%$ of the particle amount is below and $50 \%$ is above. Therefore, the distribution is separated into two halves. Graphically, the median value is established by the intersection of the cumulative distribution curve with the 50\%-line (see also Fig. 4 and Fig. 7). For screening and stereometric separation, the particle amount is given by mass, for image analysis it is given by the particle's projection area, which is continuously calculated during the recording. Consequently, the calculated fractions are either the mass of all particles in the respective size class related to the total mass (for the screening and stereometric method) or the aggregated area of all particles in a size class related to the total aggregated particle area (for image analysis) which are set as $100 \%$ sample amount.

The image analysis of particles also allows a calculation of the sphericity which is a parameter to describe the shape of a particle. Its calculation follows Eq. (1):

$\psi=\frac{C}{2 \sqrt{\pi A}}$,

where $\psi$ is the sphericity, $\psi \geqslant 1 ; C$ is the circumference of the projection area of the regarded particle; and $A$ is the projection area of the regarded particle ("shade") in image analysis.

Here, the sphericity is the measured circumference of the projection area of a particle divided by the circumference of a circle equal in size. In the case of a perfect sphere shape (round projection area), the sphericity of the particle is $\psi=1.0$. The more a particle deviates from a round shape, the higher is the sphericity. Sphericity was determined for all 13 conventional round robin fuels. Due to an accidental contamination of the standard fuels in the course of the round robin - most likely by human hairs - the sphericities of the standard fuels (SF1, SF2) could not be considered here. Other than for size distribution, sphericity is very sensitive to such contamination because small particles are treated equal to large particles in the computation of mean values.

Repeatability and reproducibility of the results were tested by comparison of the relative repeatability $(r)$ and reproducibility limits $(R)$ according to ISO 5725-1 [13]. Both parameters were calculated with the pre-setting that individual test results shall differ less or are equal to a probability $P$ of $95 \%$ under repeatability or reproducibility conditions.

\section{Results and discussion}

\subsection{Tests with standard fuels}

The results from trials with the standard fuels show that the methods tested for particle size determination (image analysis, horizontal and rotary screening) are largely incompatible. Compared to all other methods, a horizontal screening operation generally tends to overestimate the share of small particles when a classification by length is desired. If the particles are to be classified by width, there is a higher compliance of the screening results for wood chips (SF1) with the results from the image analysis. This, however, is not true for the hog fuel sample (SF2), where the reference median value (width) is overestimated by screening. This is indicated in Figs. 5 and 6 where the $100 \%$-line represents the reference value for the median of either the particle length or the particle width distribution, both determined by stereometric measurement.

For the length, which is commonly regarded as the useful fractionating criterion, the highest conformity with the reference median value is given by the measurement with the image analysis system. This applies particularly for the wood chip sample, while there is a $13 \%$ difference to the reference method for hog fuels (Fig. 5). This is probably due to a less effective singularisation for such fuel types, which may be more susceptible to overlapping positions on 


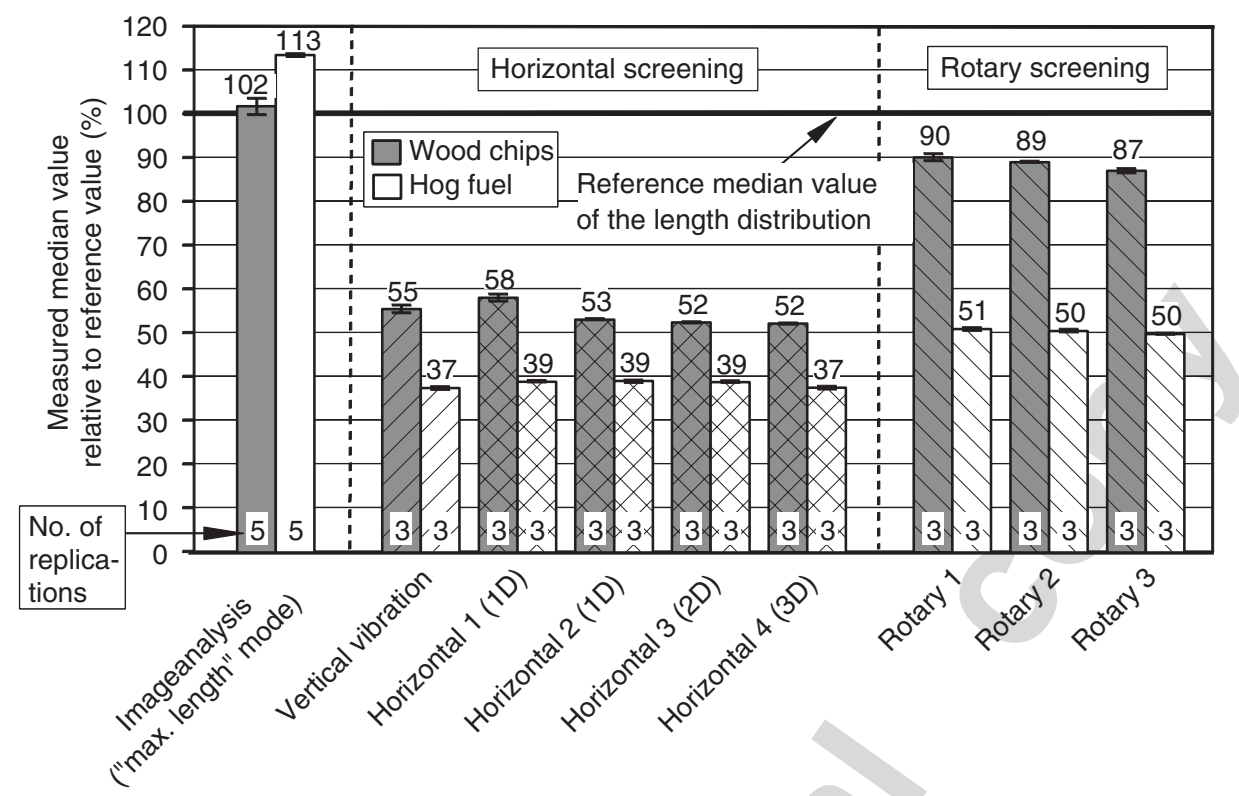

Fig. 5. Measured mean median values and standard deviations for the standard wood chips (SF1) and hog fuel (SF2) sample relative to the respective reference median value of the length distribution as determined by stereometric method (1D, 2D and $3 \mathrm{D}=$ one-, two- and three-dimensional shaking operation).

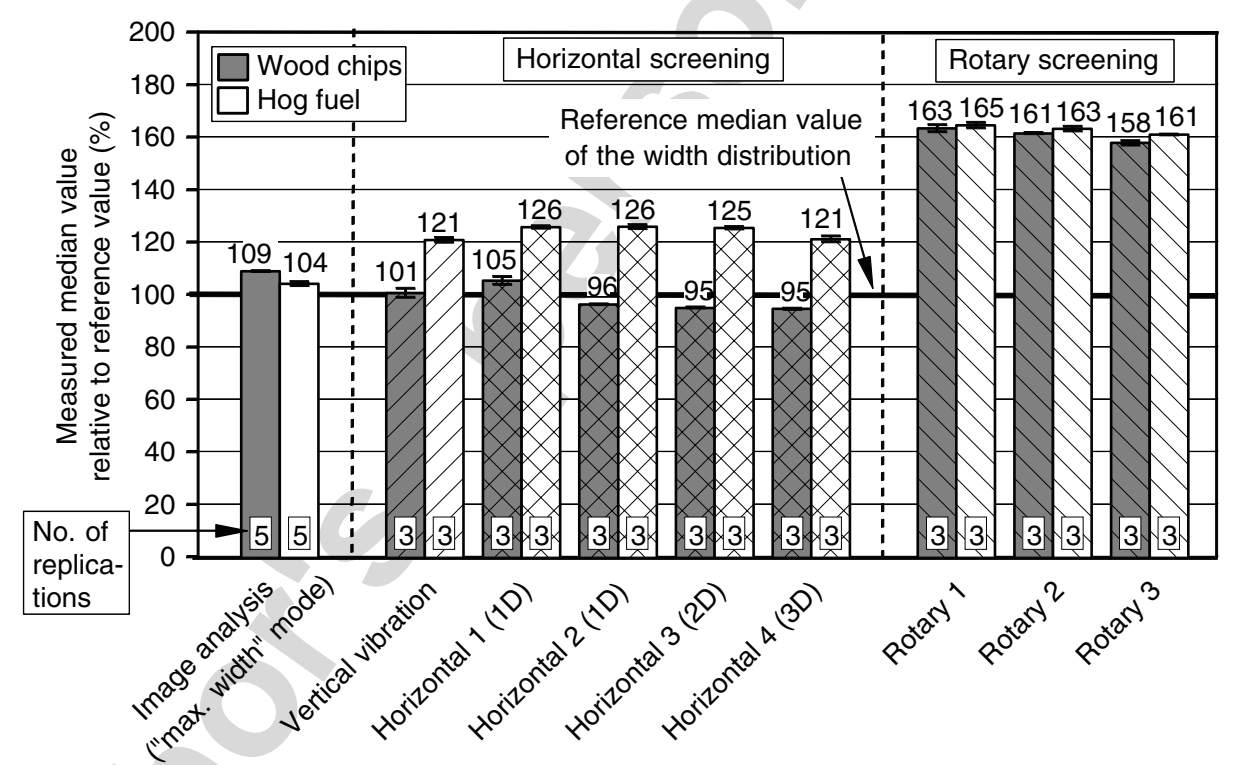

Fig. 6. Measured mean median values and standard deviations for the standard wood chip (SF1) and hog fuel (SF2) sample relative to the respective reference median value of the width distribution as determined by stereometric method.

the conveyer due to the rougher surface of hog fuels which thus may inhibit the particles to slide off from each other while being transported through the measuring plane of the camera. The higher roughness of the hog fuel particles is caused by the comminution with blunt tools which is rather a smashing than a cutting process.

For the rotary classifying system, a relatively high conformity with the reference median particle length is given when wood chips are measured (sample SF1). However, this technique has some drawbacks when using hog fuels (SF2 in Fig. 5). Nevertheless, for the chip sample
(SF1), the results from rotary screening come much closer to the reference values than those of any of the horizontal screening devices.

The underestimation of particle lengths by horizontal screening can also be read from Fig. 7, where the position of the respective size distribution curve from the screening methods was offset to the left-hand side compared to the reference length distribution curve.

For horizontal screening systems, the particle width seems to be a more decisive dimension than the particle length; this is indicated by the higher compliance with the 
reference value in Fig. 6. It can be explained by the fact that long and thin particles can pass the screen holes vertically. Such conclusions were also made for particles of less than $5 \mathrm{~mm}$ sieved by metal wire cloth screens [14].

The phenomenon of vertically passing particles is reduced by using rotary screening equipment, where the passage through the screen holes is limited by the retention time of a hole below a particle during each rotation. Consequently, long and thin particles are partly detained from slipping through the aperture. This had been intended by the designers of the equipment and therefore the rotary screen can be characterised as a measuring system for a deliberate incomplete screening. For comparable results, it is however important that the screening time, which is

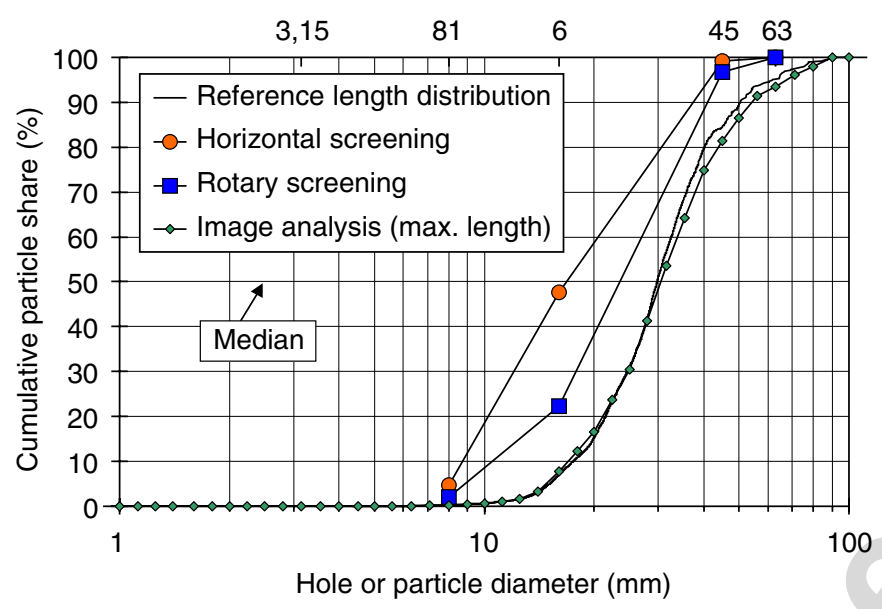

Fig. 7. Cumulative particle size distribution, examples for different testing methods applied on the standard wood chips sample. determined by a combination of angle and rotation speed, is always kept constant.

The degree to which oversized particles pass the screen holes vertically can be read from Table 2, where all wrong allocations are quantified. Their recognition was made by the different colouring of the fractions which allowed a separation by hand followed by subsequent weighing of all separated size classes on a sieve (see also Fig. 2). Thus, the misplacement in Table 2 must be interpreted as the mass of particles which do not belong on the sieve relative to the total mass of the fraction (chip colour) as determined by stereometric means according to the particle length. For larger size classes, the misplacement is higher than for smaller ones. Above $45 \mathrm{~mm}$ almost all particles are longer than the hole diameter which they pass. For image analysis, the trend is rather the opposite, as "misplacement" is in this case a function of the number of overlapping particles, but the degree of misplacement is generally much lower. As expected, the total level of particle misplacement is largely higher for hog fuel than for wood chips (see Table 2). This is true for all devices tested.

\subsection{Tests with conventional fuels}

The conventional round robin fuels (mainly wood chips and hog fuels) performed similar to the standard fuels (Table 3). Screenings of hog fuel samples, such as shredded spruce or the standard hog fuel sample (SF2), had a high relative deviation of median values to image analysis. Generally, deviations were larger when comminution was made with blunt tools. This can be read from the fact that all shredded material and the standard hog fuel sample,

Table 2

Share of misplaced particles from the two standard samples (for horizontal and rotary screens, the mean values of the participating laboratories are given)

\begin{tabular}{|c|c|c|c|c|}
\hline \multirow[t]{2}{*}{ Fraction (length in mm) } & \multirow{2}{*}{ Share of mass $(\%)$} & \multicolumn{3}{|c|}{ Shares of misplaced material ${ }^{\mathrm{a}}(\%)$} \\
\hline & & $\begin{array}{l}\text { Image analysis } \\
\text { (max. length) }\end{array}$ & Horizontal screens & $\begin{array}{l}\text { Rotary } \\
\text { screens }\end{array}$ \\
\hline \multicolumn{5}{|l|}{ Wood chip standard sample (SF1) } \\
\hline$>3.15-8$ & 0.4 & 39.4 & 3.4 & 2.2 \\
\hline$>8-16$ & 6.2 & 11.4 & 62.2 & 24.6 \\
\hline$>16-45$ & 77.4 & 3.7 & 55.5 & 21.9 \\
\hline$>45-63$ & 11.4 & 19.7 & 99.7 & 96.5 \\
\hline$>63$ & 4.7 & 6.1 & 100.0 & 100.0 \\
\hline Average misplacement ${ }^{\mathrm{b}}(\%)$ & 26.7 & 62.9 & 34.2 & \\
\hline \multicolumn{5}{|l|}{ Hog fuel standard sample (SF2) } \\
\hline$>3.15-8$ & 0.6 & 43.5 & 8.7 & 3.3 \\
\hline$>8-16$ & 6.3 & 16.7 & 57.1 & 26.8 \\
\hline$>16-45$ & 79.0 & 5.0 & 89.4 & 64.6 \\
\hline$>45-63$ & 10.5 & 10.8 & 100.0 & 99.8 \\
\hline$>63$ & 3.7 & 8.0 & 100.0 & 100.0 \\
\hline Average misplacement ${ }^{\mathrm{b}}(\%)$ & 56.0 & 88.4 & 66.9 & \\
\hline Overall average misplacement ${ }^{\mathrm{c}}(\%)$ & 41.4 & 75.7 & 50.6 & \\
\hline
\end{tabular}

${ }^{\mathrm{a}}$ Total of shares above and below cut size referring to weight of sample fraction (reference measurement).

${ }^{\mathrm{b}}$ Total of shares referring to total sample weight.

${ }^{\mathrm{c}}$ Total of shares referring to total sample weight for both standard samples (SF1, SF2). 
Table 3

Conventional and standard round robin fuels: deviations of median values from size distribution by screening devices compared to the median value as determined by image analysis (particle length)

\begin{tabular}{|c|c|c|c|c|}
\hline \multirow[t]{2}{*}{ Tested fuel } & \multirow[t]{2}{*}{$\begin{array}{l}\text { Median length (by } \\
\text { image analysis) (mm) }\end{array}$} & \multicolumn{3}{|c|}{$\begin{array}{l}\text { Relative deviation to median value by image analysis (left } \\
\text { column) }\end{array}$} \\
\hline & & $\begin{array}{l}\text { Horizontal } \\
\text { screens }(\%)^{\mathrm{a}}\end{array}$ & $\begin{array}{l}\text { Vertical } \\
\text { vibration }(\%)^{\mathrm{b}}\end{array}$ & $\begin{array}{l}\text { Rotary screens } \\
(\%)^{\mathrm{c}}\end{array}$ \\
\hline \multicolumn{5}{|l|}{ Finer fuels, P16 } \\
\hline Spruce, shredder ${ }^{\mathrm{d}}$ & 29.73 & -80.7 & -77.4 & -66.8 \\
\hline Spruce, drum chipper & 27.84 & -72.9 & -72.5 & -60.1 \\
\hline Beech, shredder ${ }^{\mathrm{d}}$ & 29.30 & -66.7 & -65.1 & -55.8 \\
\hline Spruce, standard hog fuel $(\mathrm{SF} 2)^{\mathrm{d}}$ & 33.22 & -66.1 & -67.1 & -56.3 \\
\hline Beech, drum chipper & 26.06 & -58.8 & -59.0 & -50.3 \\
\hline Poplar (SRC), disc chipper & 20.83 & -53.5 & -51.3 & -42.7 \\
\hline Spruce, disc chipper & 18.30 & -49.8 & -48.6 & -37.1 \\
\hline Beech, disc chipper & 16.36 & -49.6 & -51.1 & -35.6 \\
\hline Average & - & -62.3 & -61.5 & -50.6 \\
\hline \multicolumn{5}{|l|}{ Medium fuels, P45 } \\
\hline Spruce, logging residues, disc chipper & 38.87 & -51.7 & -49.3 & -32.1 \\
\hline Beech thinnings, disc chipper & 25.83 & -50.1 & -49.7 & -41.7 \\
\hline Spruce, logging residues, high needle content, disc chipper & 40.06 & -47.3 & -46.7 & -32.0 \\
\hline Spruce, broad range blend, disc chip. & 38.80 & -44.8 & -43.3 & -27.9 \\
\hline Spruce, standard wood chips (SF1) & 30.28 & -40.7 & -45.5 & -14.0 \\
\hline Beech, spiral chipper & 44.27 & -35.9 & -32.8 & -29.5 \\
\hline Average & - & -45.1 & -44.6 & -29.5 \\
\hline \multicolumn{5}{|l|}{ Coarse fuels, P63 } \\
\hline Spruce, spiral chipper & 67.44 & -46.1 & -44.5 & -33.6 \\
\hline Overall average & & -54.3 & -53.6 & -41.0 \\
\hline
\end{tabular}

${ }^{\mathrm{a}}$ Mean values for four horizontal screening devices.

${ }^{\mathrm{b}}$ Using flat screens in horizontal orientation.

${ }^{\mathrm{c}}$ Mean values for three rotary screening devices.

${ }^{\mathrm{d}}$ Hog fuel sample.

which are known to have been produced by a more crushing than cutting action, appear among the largest deviations in Table 3. Deviations were also higher for spruce than for beech wood which could be explained by the fact that spruce wood is mostly longer fibred and therefore any crushing action after the cutting by the chipper (e.g. in the calibration screen) will easier lead to breaks over the length axis rather than across the fibre line. This would result in more longish than round particles.

From the results, it can be seen that samples with a high mean particle sphericity - which for example means a large share of long and thin particles - have a high tendency for deviations from the image analysis results (here chosen as reference values). This is indicated by the regression analysis in Fig. 8. Although the coefficient of determination $\left(R^{2}=0.526\right)$ is relatively low, the correlation is statistically significant at the $5 \%$ error level.

For the finer fuels, which would be classified as wood chips "P16" according to the recently published European technical specification for solid biofuels [11], the deviations of the screening methods to the reference image analysis results are higher than for medium or coarse wood chips (P45 or P63). This can be read from the average results in Table 3, it reflects the different moments of inertia which the particles are exposed to before they pass a screen hole.

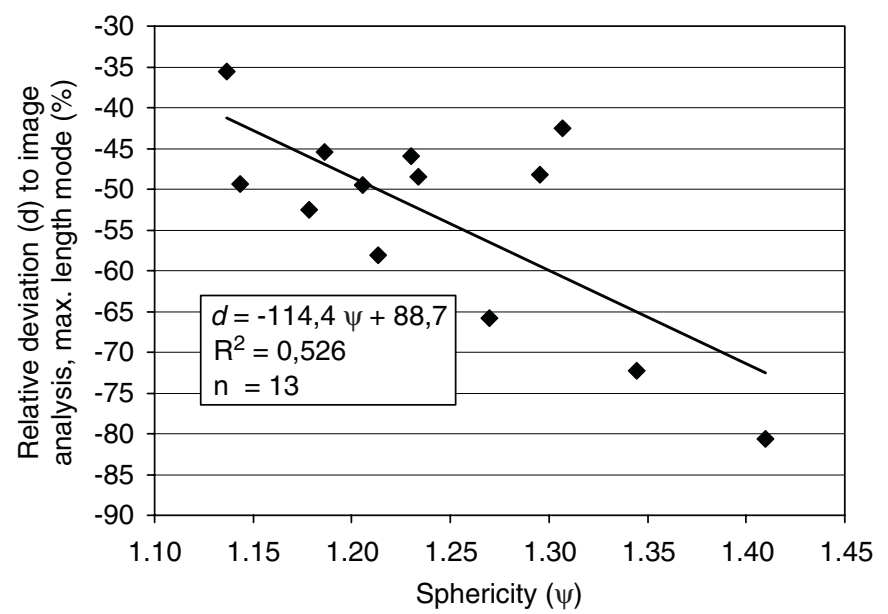

Fig. 8. Linear regression analysis for the relative deviations $(d)$ of the median values by horizontal screening ("Horizontal 1") from image analysis results as a function of the mean particle's sphericity $(\psi)$. Image analysis results gained in "max. length" mode measured with the conventional fuel samples.

Smaller particles are easier to be brought into a favourable vertical orientation towards the respective screen holes because the required torques are lower. Further explanation for the observed deviations can be seen in the fact that 
Table 4

Mean relative repeatability and reproducibility limits according to ISO 5725-1 [13] for the median values of conventional and standard fuel samples as determined by the tested measuring principles (significance level $\alpha=0.05$, probability $P=95 \%$ )

\begin{tabular}{|c|c|c|c|c|c|}
\hline Measuring principle & P16 (fine) & P45 (medium) & P63 (coarse) & Average $^{\mathrm{a}}$ & $n^{\mathrm{b}}$ \\
\hline \multicolumn{6}{|l|}{ Relative repeatability limits $r(\%)$} \\
\hline Horizontal screening & 0.9 & 1.7 & 0.9 & 1.2 & 180 \\
\hline Rotary screening & 1.2 & 1.8 & 6.3 & 1.8 & 135 \\
\hline Image analysis ("max. length" mode) & 1.9 & 3.1 & 5.4 & 2.6 & 75 \\
\hline \multicolumn{6}{|l|}{ Relative reproducibility limits $R(\%)$} \\
\hline Horizontal screening & 4.5 & 10.2 & 6.5 & 6.9 & 4 \\
\hline Rotary screening & 12.0 & 7.7 & 14.2 & 10.4 & 3 \\
\hline
\end{tabular}

${ }^{\mathrm{a}}$ Mean value for the total number of measurements.

${ }^{\mathrm{b}}$ Number of measurements for repeatability limits $r$; number of devices/laboratories for reproducibility limits $R$.

the gravimetric methods (screening) are always susceptible towards an inhomogeneous moisture distribution in the sample, while this influence can be excluded for the image analysis. If smaller particles in a sample are drying more rapidly than larger ones, they would contribute a lower mass share to the total sample mass and thus cause a displacement of the median value.

\subsection{Tests on repeatability and reproducibility}

The average relative repeatability limits $r$ for horizontal $(1.2 \%)$ and rotary screenings $(1.8 \%)$ are exceedingly low. This is shown in Table 4. For the image analysis, the repeatability was slightly worse compared to screening (particularly compared to horizontal screening devices).

The relative reproducibility limits $R$, which characterise the variation between the laboratories, cannot be compared here consistently because the image analysis was available at only one laboratory. Moreover, interpretations are difficult due to the low number of devices and laboratories involved in the round robin and the samples are subject to mechanical wear which could have contributed to the observed variation. Generally, however, the relative reproducibility limits based on the median values for horizontal and rotary screening results seem acceptable. On average, reproducibility was better for horizontal screenings than for rotary screening (Table 4).

\section{Conclusions}

Particle size analysis of biofuels is a difficult task which is associated with high measuring uncertainties if different measuring principles are applied. In horizontal screening, a severe underestimation of the particle length is given, while some improvements are found for the rotary screening method. Results from both screening methods are highly repeatable but a direct comparability is not given. The highest conformity with the reference values is given for an image analysis system. But this technology is still relatively costly, therefore its major focus of application is presumably given when large sample volumes are processed or when frequent sampling is required. As long as the widespread horizontal screening methods are still common in practice, the image analysis can preferably be applied when conformity to such measurements is not required. This applies for example in an internal quality assurance system for large biofuel suppliers or purchasers. Here the additional benefits of this technology, such as combinations with automated sampling processes or the additional measuring features (e.g., the mean particles' sphericity or the mean length-width ratio), could also be utilised. Nevertheless, it would be useful to launch a standardisation process in order to include the image analysis method to the scope of applicable standard laboratory principles for biofuels, too. This would be a first step to overcome the disadvantages of the screening methods.

\section{Acknowledgements}

The research was funded by the EU-Commission within the European project "Pre-normative work on sampling and testing of solid biofuels for the development of quality assurance systems", (BioNorm) ENK6-CT-2001-00556.

\section{References}

[1] Kristensen EF, Kofman PD. Pressure resistance to air flow during ventilation of different types of wood fuel chip. Biomass and Bioenergy 2000;18:175-80.

[2] Mattsson JE. Basic handling characteristics of wood fuel: angle of repose, friction against surfaces and tendency to bridge building for different assortments. Scandinavian Journal of Forest Research 1990;5:583-97.

[3] Jensen PD, Mattsson J-E, Kofman PD, Klausner A. Tendency of wood fuels from whole trees, logging residues and roundwood to bridge over openings. Biomass and Bioenergy 2004;26:107-13.

[4] Paulrud S, Nilsson C. The effects of particle characteristics on emissions from burning wood fuel powder. Fuel 2004;83:813-21.

[5] ANSI/ASAE S424.1 MAR98. Method for determination and expressing particle size of chopped forage materials by screening, USA, 1992.

[6] ÖNORM M 7133: Energiehackgut, Anforderungen und Prüfbestimmungen. Vienna, Austria: Austrian Standardisation Institute; 1998.

[7] SCAN-CM 40:94: Wood chips for pulp production-size distribution. Scandinavian Pulp, Paper and Board Testing Committee, 1994. 
[8] SS $1871 \quad 70$ Biofuels and peat-determination of total moisture content. Stockholm, Sweden: Swedish Standards Institute; 1997.

[9] Hartmann H, Böhm T, Bock M. Measuring size distribution of wood chips. In: Proceedings of the 12th European conference and exhibition on biomass for energy, industry and climate protection, Amsterdam: ETA-Florence and WIP-Munich; 2002. p. 215-8.

[10] Yen YK, Lin CL, Miller JD. Particle overlap and segregation problems in on-line coarse particle size measurement. Powder Technology 1998;98:1-12.
[11] $\mathrm{prCEN} / \mathrm{TS}$ 14961. Solid biofuels-fuel specifications and classes. Technical Specification; 2004.

[12] ISO 3310-2. Test sieves, technical requirements and testing; Part 2: test sieves of perforated metal plate. 3rd ed. (1990-11-01).

[13] ISO 5725-1. Accuracy (trueness and precision) of measurement methods and results - part 1: general principles and definitions. 1994.

[14] Carre J. Effect of the kind and the shape of raw material on the physical and mechanical properties of particle boards. PhD thesis, Station de Technologie forestière, ministère de l'agriculture; 1970 (in French). 